Review Article

\title{
Generation of Cholinergic and Dopaminergic Interneurons from Human Pluripotent Stem Cells as a Relevant Tool for In Vitro Modeling of Neurological Disorders Pathology and Therapy
}

\author{
Anna Ochalek, ${ }^{1,2}$ Karolina Szczesna, ${ }^{2}$ Paolo Petazzi, ${ }^{3}$ \\ Julianna Kobolak, ${ }^{2}$ and Andras Dinnyes ${ }^{1,2}$ \\ ${ }^{1}$ Molecular Animal Biotechnology Laboratory, Szent Istvan University, Pater K. Street 1, Godollo 2100, Hungary \\ ${ }^{2}$ BioTalentum Ltd., Aulich L. Street 26, Godollo 2100, Hungary \\ ${ }^{3}$ Bellvitge Biomedical Research Institute, Hospital Duran i Reynals, 3a Planta, Gran Via de l'Hospitalet 199, \\ Hospitalet de Llobregat, 08908 Barcelona, Spain \\ Correspondence should be addressed to Andras Dinnyes; andras.dinnyes@biotalentum.hu
}

Received 3 August 2016; Revised 3 November 2016; Accepted 9 November 2016

Academic Editor: Yang D. Teng

Copyright (C) 2016 Anna Ochalek et al. This is an open access article distributed under the Creative Commons Attribution License, which permits unrestricted use, distribution, and reproduction in any medium, provided the original work is properly cited.

\begin{abstract}
The cellular and molecular bases of neurological diseases have been studied for decades; however, the underlying mechanisms are not yet fully elucidated. Compared with other disorders, diseases of the nervous system have been very difficult to study mainly due to the inaccessibility of the human brain and live neurons in vivo or in vitro and difficulties in examination of human postmortem brain tissue. Despite the availability of various genetically engineered animal models, these systems are still not adequate enough due to species variation and differences in genetic background. Human induced pluripotent stem cells (hiPSCs) reprogrammed from patient somatic cells possess the potential to differentiate into any cell type, including neural progenitor cells and postmitotic neurons; thus, they open a new area to in vitro modeling of neurological diseases and their potential treatment. Currently, many protocols for generation of various neuronal subtypes are being developed; however, most of them still require further optimization. Here, we highlight accomplishments made in the generation of dopaminergic and cholinergic neurons, the two subtypes most affected in Alzheimer's and Parkinson's diseases and indirectly affected in Huntington's disease. Furthermore, we discuss the potential role of hiPSC-derived neurons in the modeling and treatment of neurological diseases related to dopaminergic and cholinergic system dysfunction.
\end{abstract}

\section{Introduction}

The majority of underlying mechanisms related to human neurological dysfunction are not fully examined. Most of the current knowledge about neurodevelopmental and neurodegenerative disorders focuses on studies of postmortem nerve tissues, spinal cords, and brains or cancer tissue (e.g., neuroblastoma). Due to the limited access to neuronal samples from postmortem organs and the restricted possibilities for directly examining live human neurons, the current understanding of the cellular and molecular mechanism of these diseases is restricted. Additionally, studies with tissues from autopsies that often represent the end stage of the disease do not always reveal information on the course of disease. A significant contribution for elucidating the pathogenesis of various neurological abnormalities has been represented by transgenic animal models that can mimic human diseases [1]. Transgenic/knockout technologies provide a useful tool for investigation of disease mechanism. However, animal models do not fully recapitulate complex human disease phenotypes and very often are limited only for monogenic disorders.

Recent discoveries in pluripotent stem cell technology provide a new opportunity to overcome these limitations. Production of human pluripotent stem cells (hPSCs) from 
different somatic lineages can be seen as a novel tool that allows the development of treatments for human neurological disorders through disease modeling, drug screening, and regenerative medicine.

Human embryonic stem cells (hESCs) first established by Thomson et al. [2] and hiPSCs developed by Yamanaka's group [3], as the main types of hPSCs, both show unlimited self-renewal properties and the ability to differentiate into cells of all three germ layers [4].

Currently, many neurological diseases show dramatically increasing trends and, with the aging populations of developed countries, potential treatments are needed urgently. Nowadays, Alzheimer's and Parkinson's diseases are the most common progressive neurodegenerative disorders in aging populations. World Alzheimer Report estimated that 46.8 million people worldwide live with dementia and over 9.9 million new cases are detected each year. By 2050, the total number of people with dementia will increase to 135 million. According to available statistics published by European Parkinson's Disease Association, around 6.3 million people are affected with Parkinson's disease worldwide. Generation of defined neural subtypes from hiPSCs to replace affected neurons in the brain may be an effective method in central nervous system (CNS) disease treatment. Furthermore, proper in vitro human cellular pathomechanisms model would be relevant. So far many different protocols were used for hiPSCs differentiation that consequently led to generation of broad numbers of neuronal subtypes: dopaminergic, cholinergic, glutamatergic, GABAergic, motor neurons, peripheral sensory neurons, and medium spiny neurons of the striatum [5]. Importantly, in Alzheimer's and Parkinson's diseases, dopaminergic and cholinergic neurons are the most frequently affected groups of neurons.

Generation of functional dopaminergic neurons from hiPSCs described in various protocols is relatively robust and reproducible, while cholinergic neurons production still requires optimization and increase efficiency. Herein, we will focus on recent accomplishments in generation of dopaminergic and cholinergic neurons and their potential use in the development of novel therapies.

\section{Generation of Specific Neural Subtypes through Pluripotent Stem Cells Differentiation}

Neuronal formation and patterning are critical for the proper wiring of the brain and they occur mostly during embryonic neurogenesis. Neuronal progenitor cells located in the neuroectodermal layer of the embryo are induced by various signaling factors to differentiate into neurons and glia. Based on the progenitor location in the developing brain, different neuronal and glia cells are produced. For instance, progenitor cells located in the ventral neural tube generate motor neurons and oligodendrocytes, while interneurons and astrocytes are produced from dorsal progenitor cells [6]. In addition to the position along the neuraxis, the fate of single neurons depends on many factors including epigenetic profile and patterning factors. Unspecified progenitor cells within the neuroectoderm can differentiate into various neural subtypes by modulating signaling pathways in which are involved bone morphogenic protein (BMP), Wingless-Type MMTV Integration Site Family (WNT) proteins, fibroblast growth factor (FGF), retinoic acid (RA), and other signaling molecules.

Numerous laboratories have established in vitro differentiation protocols to generate neurons. Initially, the methods were based on hESCs, although their use has been a source of ethical, legal, and social controversy, because of their derivation from early embryos. In 2007, Yamanaka's group has generated human iPSCs via genetic reprogramming of somatic fibroblast cells through retroviral transduction of four human transcription factors: POU domain, class 5, transcription factor 1 (POU5F1), better known from its former name octamer-binding transcription factor 4 , and therefore often abbreviated as OCT4, sex determining region Y-box 2 (SOX2), Kruppel-like factor 4 (KLF4), and $c-M Y C$ [3]. Since this discovery, hiPSCs have been considered an important source for the generation of neurons and many other types of cells. iPSCs are similar to ESCs in many aspects such as the expression of pluripotency-related genes/proteins, embryoid body formation, teratoma formation, and capability of differentiating into all three germ layers. However, the full extent of iPSCs relation to ESCs is still being assessed.

Theoretically, iPSCs and ESCs both share the property of pluripotency that can be equally used in human disorders modeling. Despite many similarities between iPSCs and ESCs, there are several differences that have significant influence on new cell generation. For instance, the analysis of gene expression profiles revealed changes between cell lines based on their origin. The "epigenetic memory" of the original somatic cells may cause some specific aberrations which impede iPSC differentiation potential [7]. As a result of prolonged in vitro propagation and the environmental culture conditions, the genome integrity of iPSCs can be impaired. Consequently, genetic aberrations may decrease the reprogramming efficiency.

Despite these not fully examined issues, several alternative differentiation protocols to obtain dopaminergic (Figure 1) and cholinergic neurons from hPSCs (Figure 2) have been developed. Human PSCs have potential to differentiate into functionally specialized cell types through the mechanism mimicking the in vivo development. Many factors such as media composition, concentration of signaling factors, plating cell density, and timing of differentiation and maturation process and physical parameters of culture system have significant influence on the type and efficiency of generated cells, such as neurons. In the next sections, we compare the different techniques generating midbrain dopaminergic neurons and basal forebrain cholinergic neurons from hPSCs. Figures 1 and 2 provide a comprehensive picture about the used methods, chemical compounds, and laboratories which published the methods. We also detailed whether the method was tested with different PSC cell sources (hESC or hiPSC).

2.1. Generation of Dopaminergic Neurons. Successful conversion of PSCs to dopaminergic (DA) neurons depends on the 
Perrier et al. 2004 [8]

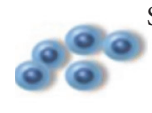

SHH, FGF8, BDNF, GDNF

hESCs

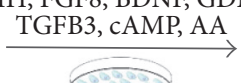

Stromal cells N2 medium

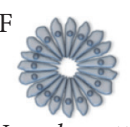

Neural rosettes

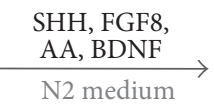

N2 medium

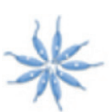

NPCs

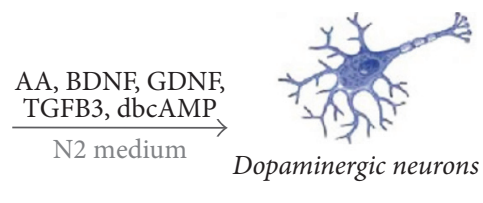

AA, BDNF, GDNF

N2 medium Dopaminergic neurons

Chambers et al. 2009 [9]

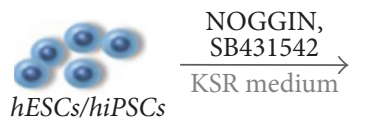

$\stackrel{\text { NOGGIN, }}{\text { SB431542 }}$
$\underset{\text { KSR medium }}{\longrightarrow}$

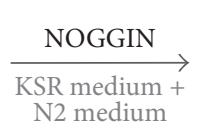

N2 medium

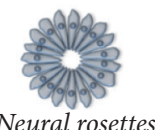

Neural rosettes

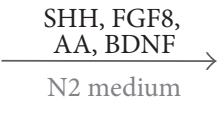

(a)

Kriks et al. 2011 [10]
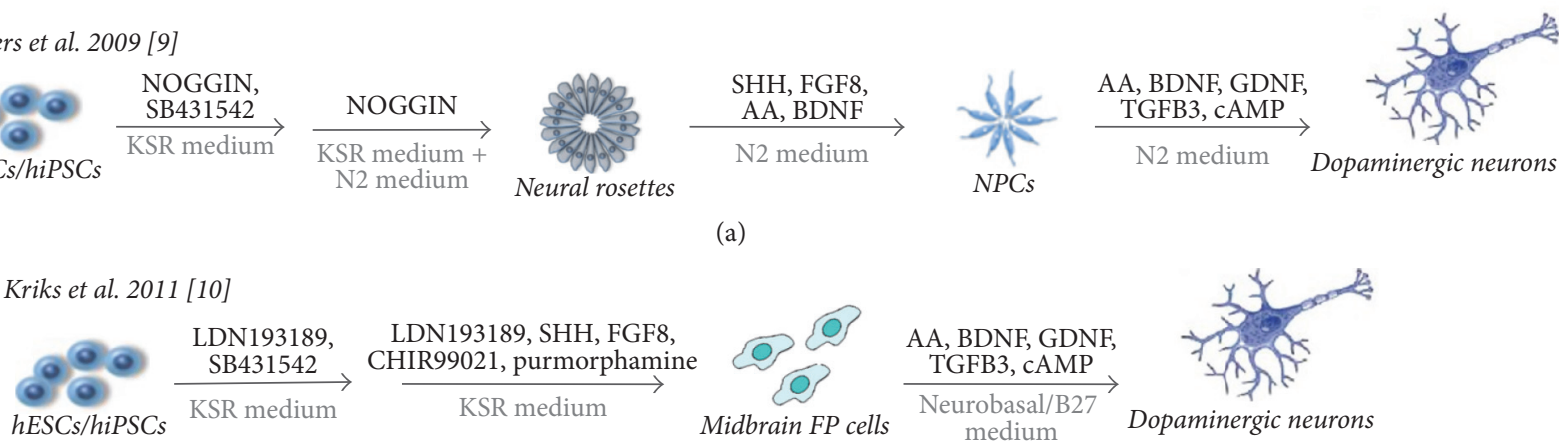

Dopaminergic neurons
Doi et al. 2014 [11]

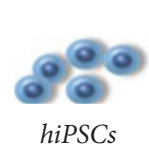

$\underset{\text { LDN193189, A83-01, }}{\stackrel{\text { FGF8, purmorphamine }}{\longrightarrow}}$ KSR-GMEM medium

LM-511E8 coated dish

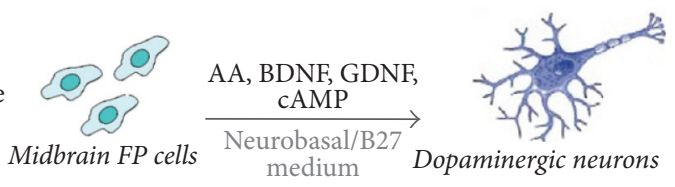

medium

(b)

FIGURE 1: Comparison of different protocols for deriving of midbrain dopaminergic neurons from hESCs and hiPSCs. (a) Methods based on mechanical neural rosettes selection. Neural differentiation was induced by coculture of hPSCs on stromal cells MS5 or S2 [8] and dual inhibition of SMAD signaling pathway (NOGGIN + TGFB inhibitor: SB431542) in the presence of knockout serum replacement (KSR) and N2 medium [9]. Rosettes structures were harvested mechanically and gently replated in the presence of growth factors. In the final step, newly generated neural progenitor cells were differentiated into DA neurons in the absence of SHH and FGF8. (b) Methods based on the floor plate (FP) induction. Dual SMAD inhibition (BMP inhibitor: LDN193189 + TGFB inhibitor: SB431542) and activation of WNT signaling by SHH and GSK3B inhibitor (GSK3Bi), CHIR99021, were used for midbrain FP cell generation from hPSCs [10]. Purmorphamine treatment was applied for FP cell patterning. hPSCs induced with LDN193189 and A83-01 (inhibitor of TGFB type I receptor ALK5) were cultured in media supplemented with purmorphamine and FGF8 to induce floor plate cells. FP cells under stimulation with growth factors generated DA neurons; recombinant E8 fragments of human laminin 511 (LM511-E8) supported the neural differentiation and cell survival [11]. Final concentration of growth factors, supplements, and inhibitors may be different in the specified protocols.

patterning and signaling factors that induce gene expression typical for endogenously developing DA neurons.

Neural stem cells (NSCs) are produced from iPSCs/ESCs that undergo induction in coculture with stromal feeder cells such as PA6 and MS5 $[8,16]$ or in feeder independent system. Neuroepithelial structure formed by NSCs is composed of rosettes that express neural markers like nestin (NES), paired box 6 (PAX6), sex determining region Y-box 1 (SOX1), and neural cell adhesion molecule (NCAM). Culture of NSCs in chemically defined neural induction medium results in differentiation of progenitor cells into different neuronal subtypes.

One of the first experiments performed on NSCs revealed that treatment of hESC-derived neural precursors with fibroblast growth factor 8 (FGF8) and sonic hedgehog ( $\mathrm{SHH}$ ) significantly increases the number of neurons expressing tyrosine hydroxylase (TH) and consequently the percentage of mature DA neurons [17]. The presence of glial cell line derived neurotrophic factor (GDNF) in culture medium additionally increases DA neuron differentiation [18].

Although FGF8 and SHH determine DA phenotype, the regional identity of the DA neurons (forebrain or midbrain phenotypes) can be specified under a chemicaldefined media composition. Recently, two groups published protocols for generation of two different types of DA neurons; however, these studies used mouse ESCs (mESCs). In the first one, progenitor cells were differentiated into midbrain DA neurons in the presence of FGF8, SHH, and ascorbic acid (AA) and their maturation was confirmed by dopamine release in the medium [19]. In the second study, stromal cells were used to induce neuronal differentiation of mESCs in serum-free conditions without any patterning factors. These stromal derived cells induced significant increase of activity that is reflected in the number of TH-positive neurons 

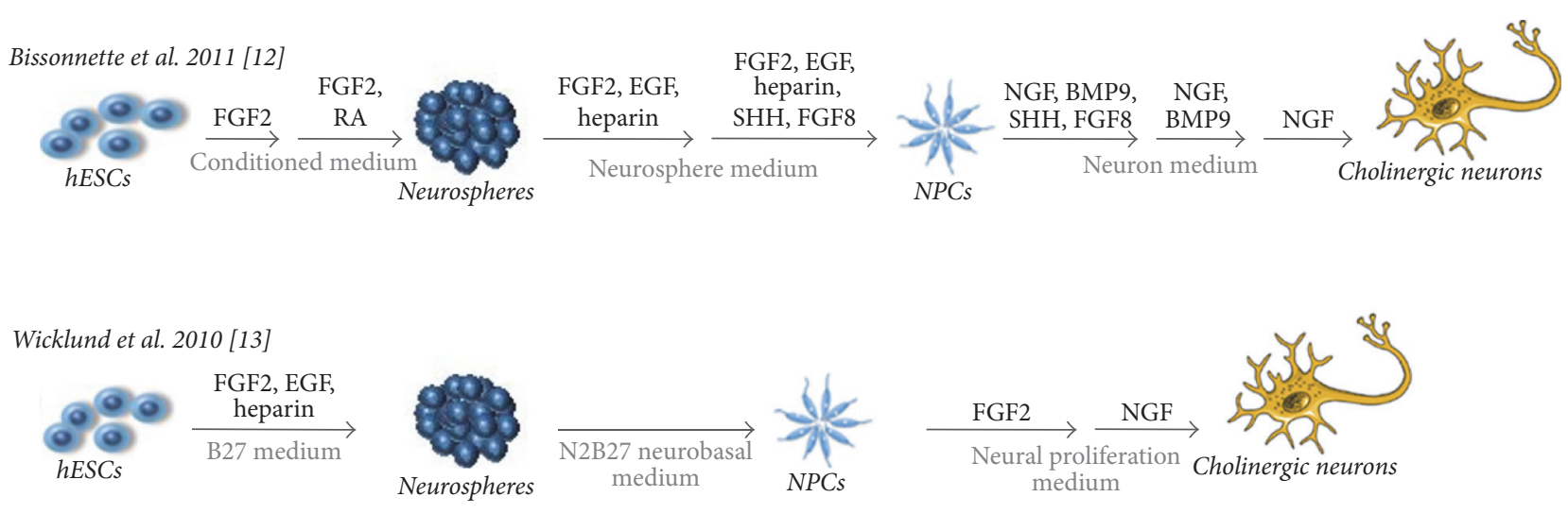

(a)

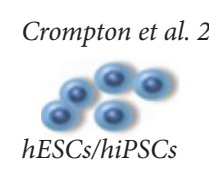

hESCs/hiPSCs

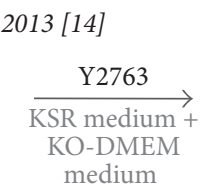

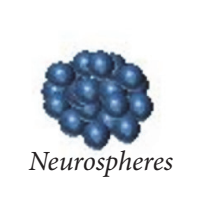

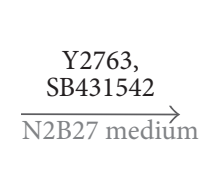

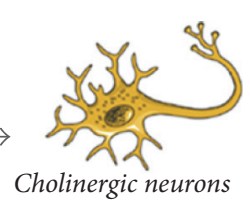
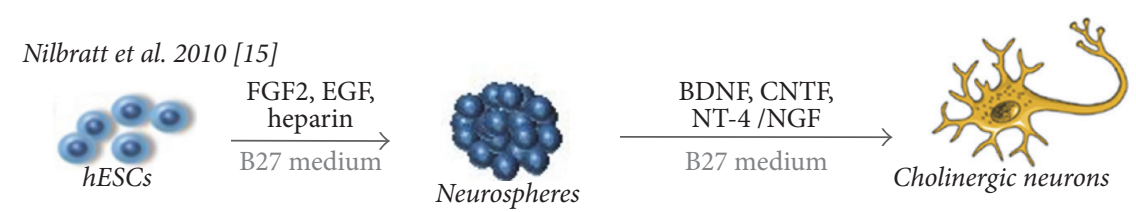

(b)

FIGURE 2: Comparison of different protocols for deriving of basal forebrain cholinergic neurons from hESCs and hiPSCs. (a) Generation of BFCNs from neurospheres through neural progenitor cell stage. Predominantly pure population of basal forebrain cholinergic neurons (BFCNs) was derived from hPSCs by using diffusible ligands presented in the forebrain during a development [12]. Pretreatment with SHH and FGF8 was used to differentiate hPSCs towards a forebrain progenitor fate [12]. Treatment with NGF promoted the differentiation into functionally mature BFCNs $[12,13]$. (b) Direct generation of BFCNs from cells growing in neurospheres. Neural development was induced in neurosphere-based nonadherent differentiation in presence of mitogens and ROCK inhibitor Y27632 [14]. Neurospheres derived from hPSCs exposed to neurotrophins, BDNF, CNTF, NT-4, and NGF, increased neuronal differentiation and cholinergic phenotype specification [15]. Composition of the basic medium can be different within the above protocols.

producing dopamine. DA neurons after transplantation into the mouse striatum remain $\mathrm{TH}$ positive, thus indicating being more forebrain-like than midbrain-like dopaminergic neurons [20]. Additional studies showed that SOX1 positive neuroepithelial cells derived from hESCs and being exposed to FGF8 and SHH generate bipolar forebrain DA neurons that expressed TH enzyme. Treatment of neuroepithelial cells in precursor stage before SOX1 expression leads to formation of midbrain DA neurons with large cell bodies and a specific midbrain marker, engrailed 1 (EN1) [21]. In most of the studies, the phenotype of DA neurons is confirmed by a wide panel of morphological and functional characteristics as follows: $\mathrm{TH}$ expression, $\mathrm{KCl}$-evoked DA release, and presence of depolarization-induced and tetrodotoxin-sensitive action potential [8]. However, the regional identity of DA neurons is not well examined due to the lack of reliable antibodies (e.g., restricted detection of dopamine transporter (DAT), mature marker in cultured human DA neurons) and different time points for release of transcription factors and DA neuronal marker expression. In mESCs, En1 transcription factor expression is overlapped with $\mathrm{TH}$ being downregulated in postmitotic TH neurons. Consequently, only low percentage of TH neurons coexpressed En1 during neuronal differentiation [22]. In addition, the maturation and functionality of DA neurons are tested in 6-hydroxydopamine- (6-OHDA-) lesioned rats. Transplantation of DA neurons derived from hPSCs improves the behavioral deficits [11]. Analysis of grafts suggests that the majority of DA neurons are generated from grafted neuronal cells and some of them can be integrated into the striatal circuitry. Dopamine release from injected neural cells triggers functional improvements in rats [22].

Fork head box protein A2 (FOXA2) is another player with important influence in the early development and later maintenance of midbrain DA neurons. Midbrain dopaminergic neurons with a stable phenotype defined by expression of FOXA2, TH, and $\beta$-tubulin were generated from hESCs 
treated with low dose of retinoic acid and high activity form of SHH. Early exposure to WNT1 and FGF8a rather than FGF8b was required for efficient differentiation of the neural progenitor cells from the floor plate (FP) into the midbrain DA neurons that express FOXA2 [23].

In 2009, Chambers et al. described the rapid and efficient conversion of hESCs and hiPSCs to neurons by the synergistic action of two inhibitors of SMAD pathway, NOGGIN, and SB431542 [9]. Single inhibition of SMAD pathway by SB431542 is associated with a dramatic decrease in the expression of NANOG and increase in caudal type homeobox 2 (CDX2) that consequently result in loss of pluripotency and differentiation through the trophoblast lineage. NOGGIN downregulates CDX2 expression and represses BMP release that drive trophoblast destiny. Only dual SMAD inhibition significantly improves the neural induction of hESCs and hiPSCs under adherent culture conditions. Exposure of cells generated via this method to $\mathrm{SHH}$ at day 5 and to FGF8 at day 9 of terminal differentiation and further culture until day 19 in medium supplemented with AA, brain derived neurotrophic factor (BDNF), GDNF, transforming growth factor beta 3 (TGFB3), and cyclic adenosine $3^{\prime}, 5^{\prime}$-monophosphate (cAMP) leads to production of Tubulin, Beta 3 Class III (TUBB3) positive neurons coexpressing $\mathrm{TH}$ [9].

Another method of midbrain DA neurons generation is based on a FP strategy. FP is formed by a group of cells with neurogenic potential located at the ventral midline of the developing neural tube. Cells in this area secrete diffusible molecules such as SHH and Netrin 1 (NTN1) that are involved in neural tube patterning and guidance of extension of commissural axons [24]. The neurogenic potential of FP cells is established by expression of transcription factors, such as EN1, orthodenticle homeobox 2 (OTX2), FOXA2 and LIM homeobox transcription factor 1 alpha $(L M X 1 A)$, which are involved in two regulatory feedback loops (SHH-FOXA2 and WNT1-LMX1A) [25]. Differentiation of PSCs to FP cells and then activation of neurogenesis are an alternative way of DA neurons generation. Human ESCs exposed to high concentration of $\mathrm{SHH}$ change the morphology and properties towards FP cells [26]. Alternatively, SHH together with WNT can be utilized to drive hPSCs to midbrain FP precursors. Generated in this way, midbrain DA neurons can be maintained several months in vitro, and, after transplantation in 6-OHDA-lesioned mice and rats, they demonstrate complete restoration of movement activity [10]. WNT1 expressed in the ventral midbrain play a critical role in activating the neurogenesis. In consequence, regulation of WNT1 and $\mathrm{SHH}$ in neural progenitor cells can lead to generation of midbrain DA neurons via the alternative route.

2.2. Generation of Cholinergic Neurons. Basal forebrain cholinergic neurons (BFCNs) are the major source of cortical cholinergic input that is necessary for memory and learning. Previous studies in animals reveal important role of BFCNs in hippocampal neurogenesis [27] and functional synaptic plasticity in developing cortex [28]. The largest and the best characterized group of forebrain cholinergic neurons is placed in the median ganglionic eminence (MGE). BFCNs are primarily affected in Alzheimer's disease. For this reason, in vitro generation of cholinergic neurons from human PSC is a crucial step for disease modeling and novel cell replacement therapy for Alzheimer's patients. However, the number of BFCNs differentiated from hPSCs is still very limited and the regional identity of generated neurons is not well characterized.

One of the first methods for the derivation of BFCNs from hESCs was based on the stimulation using diffusible ligands present in the MGE at developmentally relevant time periods [12]. The crucial step in the above experiment was differentiation of hESC-derived neural progenitor cells towards a forebrain progenitor fate by pretreatment with $\mathrm{SHH}$ and FGF8. Neural progenitors that are generated in this way and treated transiently with bone morphogenic protein 9 (BMP9) showed a significant increase in the expression of BFCN markers such as choline acetyltransferase (ChAT), acetylcholinesterase (AChE), and nerve growth factor receptors (NGFR): TrkA and neurotrophin p75. Markers for other populations of cholinergic neurons were not detected. Direct treatment of hESCs with BMP9 without SHH/FGF8 pretreatment resulted in the absence of cholinergic neurons. MGE during development expresses some transcription factors including LIM homeobox 8 ( $L H X 8)$ transcription factor [29] and gastrulation brain homeobox 1 transcription factor (GBX1) that promote BFCN differentiation [30] and are upregulated by BMP9. Transiently overexpression of $L H X 8$ and $G B X 1$ in SHH/FGF8 pretreated neural progenitors leads to appearance of a highly purified population of BFCNs with long projecting axons and coexpression of ChAT and p75 [12]. These neurons produce acetylcholine in vitro and form cholinergic synapses which were electrophysiologically functional after engraftment into murine hippocampal slice cultures.

Another method of active ChAT-positive cholinergic neurons generation focused on neurotrophic factors. The neurotrophins are growth factors that act by stimulating Trk and p75 receptors, which in turn are responsible for axonal and dendritic growth, neurotransmitter regulation, and synaptic plasticity [31]. hESCs-derived neuronal cells after stimulation with neurotrophins, BDNF, neurotrophin 3 (NTF3), ciliary neurotrophic factor (CNTF), and nerve growth factor (NGF), significantly increase the proportion of ChAT-positive neurons [15]. However, stimulation of neural progenitors with BDNF and NGF upregulates LHX8 expression in MGE areas of the embryonic forebrain, whereas CNTF induce LIM homeobox 6 transcription factor ( $\mathrm{HHX} 6$ ) expression in other subdomains of the MGE. Additional expression of NK2 homeobox 1 (NKX2-1) and ISL LIM homeobox 1 (ISL1) is associated with the development of forebrain cholinergic neurons and coexpression of p75 receptor demonstrated the presence of BFCNs. Furthermore, these differentiated neuronal cells produce $\alpha 3, \alpha 4$, and $\alpha 7$ subunits of nicotinic acetylcholine receptor and muscarinic acetylcholine receptor subtypes, M1, M2, and M3, that are displaying an important role in hESCs-derived cholinergic neurons [15]. All the above-mentioned methods used specific extrinsic factors to produce cholinergic neurons in twodimensional cultures. However, the latest study has reported 
a novel embryoid body based differentiation system for efficient induction of BFCNs [14]. Cultures of embryoid bodies in 3-dimensional systems without any additional factors stimulate intrinsic $\mathrm{SHH}$ signaling which results in expression of NKX2-1 and LHX8 [32]. Upon terminal differentiation, the basal forebrain specific NSCs generate electrically active cholinergic neurons that express TUBB3, ChAT, ISL1, and p75 and after transplantation are able to integrate into the adult rat brain [14]. In the newest study published by $\mathrm{Hu}$ et al., hPSCs were converted to NKX2-1 positive MGE cells by using high concentration of $\mathrm{SHH}$ or combination of $\mathrm{SHH}$ and purmorphamine. To increase the efficiency of BFCNs generation, MGE progenitor cells were cocultured with hPSC-derived astrocytes in the presence of NGF [33]. In the above method, around $40 \%$ of total cell population has expressed cholinergic markers that offers a potent approach to produce BFCNs from pluripotent cells.

\section{3. iPSCs Providing New Tools for Developing Treatments for Cholinergic and Dopaminergic System Dysfunctions}

Current understanding of the etiology of neurological disorders is greatly expanded. However, the mechanisms of most of these diseases remain still unclear. Furthermore, no effective treatments or disease-modifying therapy are available. Thus, patient-derived human iPSCs are a good tool for generating physiologically relevant in vitro human disease models. Stem cells technology can be applied in disease pathomechanism investigations, identification of potential drug targets, drug screening platforms, and cell transplantation.

Newly generated iPSCs from patient-derived tissues are successfully applied in modeling of human neurodegenerative diseases (e.g., Alzheimer's disease, Parkinson's disease, spinal muscular atrophy (SMA), amyotrophic lateral sclerosis (ALS), and Huntington's disease) and neurodevelopmental disorders (e.g., familial dysautonomia, Rett syndrome, autism spectrum disorder (ASD), and Down syndrome) (Table 1). In recent years, the dopaminergic and cholinergic systems have been a main focus of research in neurological pathogenesis. Efficient generation of functional dopaminergic and cholinergic neurons affected mostly in Parkinson's disease and Alzheimer's/Huntington's disease patients, respectively, can provide a crucial tool for effective treatment of the indicated dysfunctions.

3.1. Alzheimer's Disease and iPSCs. Alzheimer's disease (AD) is an age-related neurodegenerative disorder and the most common type of dementia in humans, affecting one in eight adults over 65 [34]. Two main pathological hallmarks of $\mathrm{AD}$ are extracellular plaques of aggregated amyloid beta $(\mathrm{A} \beta)$ protein and intracellular neurofibrillary tangles (NFTs) composed of aggregated tau, a microtubule binding protein. These $\mathrm{AD}$ features have different deleterious effect on neurons. $\mathrm{A} \beta$ can disrupt synaptic plasticity including long-term potentiation (LTP), while NFTs may compromise intracellular transport and, together with $\mathrm{A} \beta$, induce mechanisms responsible for synaptic loss and neuronal death.
Neurodegeneration in $\mathrm{AD}$ evolves sequentially through certain brain regions and selected subpopulations of vulnerable neurons. Among the general cortical impairment, BFCNs are one most affected cell type in AD. Decreased level of acetylcholine (ACh) released by cholinergic nerve terminals is associated with loss of cholinergic neurotransmission and significant deterioration of cognitive functions in AD patients. Reduced choline uptake, ACh release, and presynaptic cholinergic deficiency correlate with accumulation of $\mathrm{A} \beta$ protein and intracellular NFTs. Furthermore, analysis of $\mathrm{AD}$ brain revealed reduced number of nicotinic and muscarinic $\mathrm{M} 2 \mathrm{ACh}$ receptors on presynaptic cholinergic neurons, whereas the number of M1 and M3 receptors on the postsynaptic terminals has remained unaffected. Some studies have shown that reduced cholinergic activity may stimulate higher tau hyperphosphorylation through increased activity of protein kinase C (PKC) [35]. As a consequence of disturbed neurotransmission balance, tau phosphorylation and $\mathrm{A} \beta$ protein accumulation are increased, and these lead to enhanced neurodegeneration. BFCNs degeneration contributes to attention deficits, increased spatial memory decline, and further impairment in the coding of new episodic memories [36].

Centrally acting drugs that inhibit cholinesterase such as tacrine, donepezil, rivastigmine, and galantamine have been shown to provide modest symptomatic benefit in individuals with AD [37]. AChE inhibitors together with muscarinic receptor agonists are able to restore cholinergic balance and decrease $A \beta$ deposition [38].

Recently, some groups have developed an AD disease model using iPSCs. Neurons derived from iPSCs generated from familial AD (fAD) patients carrying mutations in genes encoding amyloid precursor protein (APP), presenilin 1 (PSEN1), and presenilin 2 (PSEN2) provide an innovative tool to elucidate AD etiology and develop efficient therapeutics.

The sequential proteolytic cleavages of APP by $\beta$ secretases and $\gamma$-secretases result in the generation of $\mathrm{A} \beta$. While $\gamma$-secretases cleave C-terminal fragments of APP (APP-CTF) which leads to production of multiple length variants of $\mathrm{A} \beta$, longer variants of $\mathrm{A} \beta(\mathrm{A} \beta 42, \mathrm{~A} \beta 43)$ are more prone to aggregation than shorter ones $(\mathrm{A} \beta 38, \mathrm{~A} \beta 40)$ and they are considered more pathogenic [39].

Kondo et al. generated an AD iPSCs model from patients with E693 deletion in APP gene. Neurons with this mutation accumulated intracellular $A \beta$ oligomers that led to endoplasmic reticulum (ER) and oxidative stress. Furthermore, the accumulated $\mathrm{A} \beta$ oligomers were not proteolytically resistant, and the treatment of $\mathrm{AD}$ neural cells with docosahexaenoic acid (DHA) alleviated the stress responses [40]. These results suggest that DHA may be an effective drug for a subset of patients, making iPSC technology a useful tool for validation and identification of potential drugs. Muratore et al. described iPSCs from fAD with mutation in APP (V717I). This mutation results in higher APP expression, elevated $\mathrm{A} \beta 42, \mathrm{~A} \beta 38$ production, and increase in levels of total and phosphorylated Tau in neurons [41]. In another study, iPSCs derived neurons from fAD patients with a duplicated APP gene showed increase of secreted A $\beta 1-40$, relative level of phospho-Tau, and active glycogen synthase 
TABLE 1: Neurological disorders modeled with patient-specific human induced pluripotent stem cells.

\begin{tabular}{|c|c|c|c|c|c|}
\hline Disease & $\begin{array}{c}\text { Genetic } \\
\text { background }\end{array}$ & Disease related phenotype & Affected neurons & iPSCs model & References \\
\hline \multicolumn{6}{|c|}{ Neurodegenerative disorders } \\
\hline $\begin{array}{l}\text { Alzheimer's } \\
\text { disease }\end{array}$ & $\begin{array}{c}\text { PS1, PS2, APP } \\
\text { duplication, ApoE }\end{array}$ & $\begin{array}{l}\text { (i) Increased } A \beta 42 \text { secretion; } \\
\text { (ii) } A \beta \text { plaque formation; } \\
\text { (iii) increased phospho-Tau; } \\
\text { (iv) increased GSK } 3 \beta \text { activity }\end{array}$ & $\begin{array}{l}\text { Basal forebrain } \\
\text { cholinergic neurons; } \\
\text { cortical neurons }\end{array}$ & $\begin{array}{l}\text { (i) AD iPSCs with E693 } \\
\text { deletion in APP gene; } \\
\text { (ii) AD iPSCs with mutation } \\
\text { in APP (V717I); } \\
\text { (iii) AD iPSCs with a } \\
\text { duplication APP gene; } \\
\text { (iv) AD iPSCs with PS1 } \\
\text { (A246E) and PS2 (N141I) } \\
\text { mutation }\end{array}$ & {$[40-43]$} \\
\hline $\begin{array}{l}\text { Parkinson's } \\
\text { disease }\end{array}$ & $\begin{array}{l}\text { SNCA, LRRK2, } \\
\text { PARKN, PINK1, } \\
\text { UCHL1, GBA }\end{array}$ & $\begin{array}{l}\text { (i) } \alpha \text {-Synuclein accumulation; } \\
\text { (ii) reduced numbers of } \\
\text { neuritis; } \\
\text { (iii) increased susceptibility to } \\
\text { oxidative stress; } \\
\text { (iv) accumulation of } \\
\text { ER-associated degradation } \\
\text { substrates }\end{array}$ & $\begin{array}{l}\text { Dopaminergic } \\
\text { neurons }\end{array}$ & $\begin{array}{l}\text { (i) PD iPSCs with triplication } \\
\text { of the SNCA; } \\
\text { (ii) PD iPSCs with } \\
\alpha \text {-synuclein mutation (A53T); } \\
\text { (iii) PD iPSCs with G2019S } \\
\text { mutation in LRRK2 gene; } \\
\text { (iv) PD iPSCs with mutation } \\
\text { in PINK1 }\end{array}$ & {$[53,54,57,63]$} \\
\hline
\end{tabular}

(i) Reduced SMN gene

expression;

(ii) Fas ligand-mediated

apoptosis of $\mathrm{MN}$;

(iii) increased level of caspase

SMA

SMN1, SMN2 3, caspase 8, and membrane-bound Fas ligand;

(iv) reduced size, axonal

elongation, and

neuromuscular junction production

(i) Neurofilament-L aggregation in neuritis;

ALS

SOD1, TDP-43,

(ii) axonal degeneration;

FUS, VAPB

(iii) increased secretion of

TDP-43;

(iv) exhibited shortened

neurites (i) Increased vulnerability to

cell stressors and BDNF

withdrawal;

(ii) impaired lysosomal activity;

Huntington's

HTT (CAG

(iii) mitochondrial
fragmentation;

repeats)

(iv) alterations in

transcription repressor

activity;

(v) enhanced caspase 3/7

activity

Neurodevelopmental disorders

(i) Reduced IKAP protein

level;

(ii) cell migration deficiency;

(iii) defects in neurogenic

Familial

Dysautonomia

IKBKAP
Sensory neurons; (i) FD iPSCs with mutation in autonomic neurons IKBKAP gene

\section{differentiation;}

(iv) decreased in number of myelinated small fibers and intermediolateral column neurons (i) ALS iPSCs with A4V SOD1 mutation;

(ii) ALS iPSCs with D90A

SOD1 mutation;

Motor neurons

(iii) ALS iPSCs with mutation

[66-68]

invTDP-43 gene;

(iv) ALS iPSCs with VAPB

(P56S) mutation

$[64,65]$

(i) iPSCs with HTT mutation

Cortical neurons; from homozygous and

GABAergic medium heterozygous HD patients spiny neurons HD72-iPSC in the YAC128 model of HD 
TABLE 1: Continued.

\begin{tabular}{|c|c|c|c|c|c|}
\hline Disease & $\begin{array}{c}\text { Genetic } \\
\text { background }\end{array}$ & Disease related phenotype & Affected neurons & iPSCs model & References \\
\hline Rett syndrome & $\begin{array}{l}\text { MECP2e1, } \\
\text { MECP2e 2 }\end{array}$ & $\begin{array}{l}\text { (i) Reduced soma size; } \\
\text { (ii) altered dendritic spine } \\
\text { density; } \\
\text { (iii) dysfunction in action } \\
\text { potential; } \\
\text { (iv) alterations in synaptic } \\
\text { function; } \\
\text { (v) defects in synaptic } \\
\text { plasticity }\end{array}$ & $\begin{array}{c}\text { Glutamatergic } \\
\text { neurons }\end{array}$ & $\begin{array}{l}\text { (i) RS iPSCs with MECP2 } \\
\text { mutation }\end{array}$ & {$[74,75]$} \\
\hline ASD & $\begin{array}{l} \\
\text { NLGN1, NLGN3, } \\
\text { SHANK2, } \\
\text { SHANK3, NRXN1, } \\
\text { NRXN3 } \\
\end{array}$ & $\begin{array}{l}\text { (i) Reduced glial } \\
\text { differentiation; } \\
\text { (ii) altered gene expression } \\
\text { related to cell adhesion and } \\
\text { neuron differentiation; } \\
\text { (iii) deficits in neuronal } \\
\text { specification, synapse } \\
\text { formation and excitatory } \\
\text { neurotransmission }\end{array}$ & Cortical neurons & $\begin{array}{l}\text { (i) ASD iPSCs with functional } \\
\text { knockdown of NRXN1 gene; } \\
\text { (ii) ASD iPSCs with SHANK3 } \\
\text { deletion }\end{array}$ & {$[76,77]$} \\
\hline Down syndrome & $\begin{array}{c}\text { trisomy of } \\
\text { chromosome } 21 \\
(\text { HSA21) }\end{array}$ & $\begin{array}{l}\text { (i) Alterations in neurogenesis } \\
\text { and synaptogenesis; } \\
\text { (ii) elevated APP and A } \beta 42 \\
\text { expression; } \\
\text { (iii) Tau protein } \\
\text { hyperphosphorylation; } \\
\text { (iv) poorly developed neural } \\
\text { network; } \\
\text { (v) overproduction of reactive } \\
\text { oxygen species }\end{array}$ & Neurons in the brain & $\begin{array}{l}\text { (i) DS iPSCs with three pairs } \\
\text { of chromosomes } 21 \\
\text { (T21-iPSCs); } \\
\text { (ii) isogenic iPSCs from DS } \\
\text { individuals; } \\
\text { (iii) DS iPSCs with trisomy } 21 \\
\text { deletion through TKNEO; } \\
\text { (iv) DS iPSCs with trisomy } 21 \\
\text { deletion through Xist }\end{array}$ & {$[70,78-80]$} \\
\hline Schizophrenia & DISC1 & $\begin{array}{l}\text { (i) Decreased neuronal } \\
\text { connectivity; } \\
\text { (ii) synaptic deficits; } \\
\text { (iii) PSD95 downregulation; } \\
\text { (iv) fewer neurites }\end{array}$ & Neurons & $\begin{array}{l}\text { (i) iPSCs from schizophrenia } \\
\text { patients; } \\
\text { (ii) SZ iPSCs with a mutation } \\
\text { in DISC1 gene }\end{array}$ & {$[81,82]$} \\
\hline
\end{tabular}

kinase 3 beta (GSK3B). Treatment of the neurons with $\beta$ secretase inhibitors significantly reduced the relative level of phospho-Tau and active GSK3B [42]. fAD-derived iPSCs with PSEN1 (A246E) and PSEN2 (N141I) mutations were also established. In both cases, neuronal cells had increased $\mathrm{A} \beta 42$ secretion and $\mathrm{A} \beta 42 / 40$ ratio [43]. The treatment with $\gamma$-secretase inhibitors reduced $\mathrm{A} \beta 40$ and $\mathrm{A} \beta 42$ production in mutant neurons. The above-presented findings on iPSCs derived from patients are a good method of recapitulation of $\mathrm{AD}$ phenotype in vitro and can be used for drug discovery and improve disease modeling.

In recent time, few groups successfully generated iPSCs from sporadic $\mathrm{AD}(\mathrm{sAD})$ patients that represent more than 95\% of all AD cases. sAD iPSCs showed similar phenotype to $\mathrm{AAD}$ iPSCs including increase of secreted $\mathrm{A} \beta$, high level of ER and oxidative stress, and accumulation of enlarged RAB5positive early endosomes [42]. However, there is still limited information about the clinical onset and course of sAD. Newly developed models, mostly based on 2-dimensional (2D) culture system, may not reflect affected neurons in the brain. Due to the limited studies, it is difficult to predict whether neurons derived from sAD iPSCs show pathological phenotype and are able to reveal molecular basis of disease development. To evaluate a real value of SAD derived iPSCs, a long-term culture in 3-dimensional (3D) system may be required. Furthermore, integration of microglia in neuronal culture together with environmental cues mimicking sAD risk factors might significantly improve in vitro-based experimental sAD models.

According to the recent data, animal and nonneuronal cellular models used in pharmaceutical compound validation cannot sufficiently model the drug responses of human neurons. Therefore, there is an increasing trend to test potential drugs for the treatment of Alzheimer's disease using patientderived iPSC based systems.

Based on the fact that mutation in APP or in the $\gamma$ secretases components, PSEN1 and PSEN2, lead to increased $\mathrm{A} \beta 42 / \mathrm{A} \beta 40$ ratio and total $\mathrm{A} \beta$ level, several drugs such as $\beta$-secretase and $\gamma$-secretase inhibitors have been developed $[44,45]$. Nonsteroidal anti-inflammatory drugs (NSAIDs) were identified as $\gamma$-secretase modulators (GSMs) that lower A $\beta 42$ production by targeting $\gamma$-secretase or APP [46]. 
The studies performed on iPSC-derived neurons from $\mathrm{AD}$ patients have shown that indometacin, ibuprofen, diclofenac, and flurbiprofen significantly reduced the $\mathrm{A} \beta 42 / \mathrm{A} \beta 40$ ratio [46]. Treatment with $\gamma$-secretase inhibitor, $\mathrm{N}-[\mathrm{N}-(3,5-$ difluorophenacetyl)-1-alanyl]-S-phenylglycine t-butyl ester (DAPT), or $\gamma$-secretase activating protein (GSAP) inhibitor, imatinib, resulted in strong decrease of $\mathrm{A} \beta 40$ and $\mathrm{A} \beta 42$ level. Inhibition of $A \beta 40$ secretion by SC-560 led to increased $\mathrm{A} \beta 42 / \mathrm{A} \beta 40$ ratio. Other tested molecules including aspirin, naproxen, and Rho-associated coiled-coil forming protein serine/threonine kinase (ROCK) inhibitor Y-27632 had no significant effect on the neurons [46].

3.2. Parkinson's Disease and iPSCs. Parkinson's disease (PD) is the second most common progressive neurodegenerative disorder. Patients with PD manifest a wide range of symptoms, encompassing slowness of movement, rigidity, a lowfrequency rest tremor, and difficulty with balance. These crucial motor impairments of PD are due to the degeneration of dopamine containing neurons in the substantia nigra pars compacta (SNC) with an accompanying loss of dopamine and its metabolites in the striatum [47].

The majority of PD cases are sporadic; only $10-20 \%$ patients present familial monogenic form of disease. Mutations in genes, synuclein alpha (SNCA), leucine-rich repeat kinase 2 (LRRK2), Parkin RBR E3 Ubiquitin Protein Ligase (PARK2), PTEN-induced putative kinase 1 (PINK1), ubiquitin carboxyl-terminal esterase L1 (UCHL1), and betaglucocerebrosidase $(G B A)$, lead to pathogenic changes in the brain [48].

At the pathological level, PD is characterized by the cytoplasmic accumulation of aggregated proteins with a halo of radiating fibrils and a less defined core known as Lewy body. Another PD-specific feature is the increase of oxidative stress, which is caused by glutathione depletion, iron deposition, increased markers of lipid peroxidation, oxidative DNA damage and protein oxidation, and decreased expression and activity of mitochondrial complex 1 in the SNC [49].

Several groups revealed dysfunction of basal forebrain cholinergic system in PD patients that was confirmed by the presence of Lewy body in neurons of the nucleus basalis of Meynert, the main source of cholinergic neurons in the brain [50]. Additional study has indicated a loss of presynaptic cholinergic markers in cortex, decrease of muscarinic and nicotinic receptor binding sites, and reduced ChAT activity in the neocortex, hippocampus, and substantia nigra. Impaired distribution of pre- and postsynaptic cholinergic receptors can correlate with PD attenuation.

Recent data have shown that the loss of DA neurons in PD corresponds with alterations of M4 receptor in cholinergic neurons. In consequence, ACh level in the striatum is increased and that contributes to the development of the motor signs like tremors and dyskinesia in PD patients [35].

Unlike most other neurodegenerative disorders, there is an effective temporary symptomatic treatment for PD consisting of dopamine replacement with levodopa or dopamine agonists [51]. On the other hand, since the neurodegeneration in $\mathrm{PD}$ is progressive and there is no efficient regenerative therapy, patients eventually become quite disabled. Therefore, the inhibition of postsynaptic muscarinic receptor resulting in ACh secretion decrease and upregulation of presynaptic nicotinic receptors secreting dopamine can provide a new therapeutic strategy in PD treatment.

The iPSC technologies provide an opportunity to study PD phenotypes and mechanisms in familial and sporadic cases and to identify potential drugs.

One of the first models of familial PD was iPSCs generated from a patient with triplication of the SNCA gene, which encoded a synaptic vesicle-associated protein in Lewy bodies. DA neurons derived from this patient exhibit increased SNCA expression and susceptibility to oxidative stress [52]. Other researchers generated iPSCs from patients with the most common SNCA mutation, A53T. Compared with controls, these cells produced more nitric oxide and 3-nitrotyrosine (3-NT) and showed accumulation of ERassociated degradation substrates [53]. DA neurons differentiated from iPSCs derived from patients with G2019S mutation in $L R R K 2$ gene demonstrated increased expression of key oxidative stress response genes: $H S P B 1, N O X 1, M A O B$, and upregulation of $S N C A$. The mutant neurons were also more sensitive to stress agents: hydrogen peroxide, the proteasome inhibitor MG132, and 6-OHDA [54]. Another study showed that DA neurons developed from iPSCs of either sporadic PD or LRRK2 PD showed similar phenotypes including higher level of SNCA, the accumulation of SNCA, and reduced numbers of neurites [55]. If these results will be reproducible, they may give us a possibility to model also idiopathic PD cases in the future. Despite the unknown causes of this disorder, a small proportion of idiopathic PD cases can be attributed to known genetic factors. Although generation of iPSCs from idiopathic PD patients was established, it is still not confirmed whether PSC-derived DA neurons demonstrate phenotypes that are evidently detectable and related to PD in vitro [56]. Due to the unknown mechanisms leading to sporadic $\mathrm{PD}$, that may result from a combination of genetic and environmental factors, the use of isogenic control for comparative studies is not possible. However, an increased number of cell lines generated from patients could make iPSC models more reliable in the context of complex diseases such as sporadic $\mathrm{PD}$.

The main DA neurons were also generated from iPSCs carrying mutation in PINK1. This gene encodes a mitochondrial kinase which protects cells against mitochondrial stress and control degradation of mitochondria. DA neurons with this defect upon treatment with the mitochondrial stress inducer increase level of peroxisome proliferator-activated receptor gamma, coactivator 1 alpha (PPARGC1A) regulator of mitochondrial biogenesis, and the number of mitochondria [57]. The above results show that not only genetic background of neurons but also their exposure to the relevant stressors may be necessary for proper modeling of disease phenotype using iPSCs. DA neurons carrying the mutation in PARK2 gene increase the transcription of monoamine oxidases and significantly block DA uptake that leads to higher DA release. Insertion of the correct form of the mutant gene rescues the phenotype. It suggests that PARK2 controls dopamine neurotransmission and suppresses dopamine 
oxidation [58]. These results provide a physiologically relevant platform to screen the novel targets of disease-modifying therapies in PD.

Recently, it was shown that iPSCs can be successfully transplanted into PD animal models. iPSCs efficiently stimulated into NPCs and injected into the brain give rise to neuronal and glia cells that are functionally integrated with the neural tissues and have mature neuronal activity. Midbrain DA neurons differentiated from hiPSCs upon transplantation into the adult brain were able to improve the behavioral phenotype of rats affected by PD [59]. Another study showed that DA neurons generated from PD iPSCs and transplanted into the striatum of 6-OHDA-lesioned rats developed axons projections [60]. Rhee et al. demonstrated that transplantation of DA neurons derived from proteinbased hiPSCs into rats with striatal lesions can rescue motor deficits [61]. In 2005, Kishi et al. have demonstrated a possible role of estrogen in the transplantation of NSCs for Parkinson's disease. $17 \beta$-estradiol, estrogen hormone, increased the number of TH-positive DA neurons in vitro. The above effect was abrogated by an estrogen receptor antagonist, ICI182780, that confirmed a role of ERs in differentiation of DA neurons [62]. Due to the presence of ERs in NSCs and DA neurons, increase in TH-positive neurons was associated with the supporting effect of estrogen on neural differentiation of iPSCs and DA neuron maturation [62].

3.3. Huntington's Disease and iPSCs. Huntington's disease (HD) is an inherited progressive disorder that affects around 1 in 10,000 people. The specific features of HD comprise dystonia, motor incoordination, and cognitive and emotional impairments [83]. Cause of the disorder is an expanded CAG triplet coding for polyglutamine in the HD gene product, called the huntingtin (HTT) protein. The normal function of this protein is poorly understood with some evidences of an involvement with cytoskeletal function.

At the pathological level, HD is characterized by selective neuronal vulnerability. The first area affected by HD is the caudate-putamen that is part of the corpus striatum region. Within this brain region, medium spiny GABA neurons are severely impaired, with up to $95 \%$ loss in later stages of disease (reviewed in [84]). Moreover, there are intranuclear inclusion bodies and perinuclear and neuritic aggregates of HTT in HD neurons. Early genetic studies on HD revealed that the length of the triplet repeat expansion of CAG is positively correlated with the severity of the disease. Glutamate toxicity, oxidative stress, and autophagy inhibition are stressors that stimulate CAG expansion and result in higher cell toxicity [5].

Some studies in human and mouse models indicated that also cholinergic system is affected in HD patients. The cholinergic neuron abnormalities were demonstrated by the observations that ChAT activity is reduced in the striatal tissue of the brain and ACh release is significantly decreased [85]. It was confirmed that vesicular acetylcholine transporter (VAChT) and ChAT genes are regulated by the repressor element-1 silencing transcription factor/neuron restrictive silencer factor (REST/NRSF) [86]. Interaction of REST/NRSF with mutant HTT protein leads to repression of few neuronal specific genes such as BDNF and can cause a decrease of cholinergic marker expression. During the studies performed by Smith et al., decreased level of ChAT in striatum of HD mice correlated with the amount of HTT aggregates in cholinergic neurons. These results suggest that the defect observed in cholinergic neurons depends on the mechanism controlled by mutated HTT [85].

Recently, AChE inhibitors such as tacrine were proposed to be potential drugs for HD treatments due to their ability to restore the cholinergic system. Choline, physostigmine, donepezil, and other potential drugs in HD treatment are being tested now; however, their ability to restore a memory and reduce the hyperkinesia seems to be very limited [35].

HD neural cells derived from iPSCs displayed disease associated phenotype including changes in metabolism, electrophysiology cells adhesion, and cell toxicity. Differentiated $\mathrm{HD}$ cells with expanded CAG repeats showed changes in gene expression, including cadherin family and TGFB pathways. Additionally, cells had abnormalities in oxygen consumption and were more vulnerable to cell stressors and BDNF withdrawal [69]. In other studies, HD-generated iPSCs presented impaired lysosomal activity, mitochondrial fragmentation, and alterations in transcription repressor activity [5]. Park et al. differentiated HD specific neural stem cells derived from patient iPSC into striatal neurons. In these neuronal cells, an enhanced caspase 3/7 activity was detected [70]. HD iPSCs after treatment with inhibitor of mitochondrial fission related protein: dynamin 1-like (DNM1L) increased cell viability [66]. During in vivo studies performed by Jeon and coworkers, HD-derived neuronal progenitor cells were transplanted into HD rat with excitotoxic striatal lesions. Behavioral recovery was observed, even though the injected cells have revealed HD phenotype [87]. Above studies suggest that mutation correction in iPSCs is required for effective treatment of HD.

Drug screening and test of novel therapies using HD iPSC-derived neuronal cells include application of stressors such as glutamate toxicity, oxidative stress, DNA damage, or growth factor withdrawal [88] to test molecules counteracting the effects. For instance, the tumor necrosis factor-alpha (TNF $\alpha$ ) inhibitor XPro-1595 decreased cytokine induced apoptosis in neurons derived from iPSCs with 43 CAGs [89]. Adenosine receptor 2A agonists CGS-21680 and APEC reduced oxidative stress toxicity in the cells exposed to $\mathrm{H}_{2} \mathrm{O}_{2}$ by decreased $\gamma$-H2A Histone Family Member X $(\gamma \mathrm{H} 2 \mathrm{AX})$ induction and caspase 3 cleavage [90].

Other studies have shown that G-protein coupled receptor 52 (GPR52) is involved in mutant huntingtin toxicity. GPR52 knockdown as well as the microRNA 196a (miR196a) reduced huntingtin aggregates in neuronal culture [91]. Additionally, GPR52 knockdown lowered caspase 3 activity in response to BDNF withdrawal. Moreover, the number of condensed nuclei after BDNF withdrawal was reduced by peroxisome proliferator-activated receptor gamma (PPAR $\delta$ ) activator (KD3010) [92]. Many research groups have described drug effect of BDNF or FGF/LIF withdrawal, considered as a stress factor on cell survival [88]. Inhibitor of ataxia-telangiectasia mutated (ATM) protein, a kinase involved in the DNA damage response, apoptosis, and cellular homeostasis, KU60019, applied on the 109 and 180 CAG mixed neuronal cell cultures has shown reduced BDNF 
withdrawal-induced increases in TUNEL-positive nuclei and reduced caspase 3 activity [93]. In 2015, Ring at al. demonstrated that TGF- $\beta$ signaling pathway is altered in HD NSC with 72 CAGs that leads to higher expression of TGF- $\beta$. Furthermore, TGF- $\beta 1$ plays neuroprotective role in the NSC models and together with netrin-1 can reduce caspase 3/7 activity [94].

Effects of compounds on PSCs phenotypes not related to a stressor addition have been tested by Charbord et al. The studies were associated with increased activity of the transcriptional repressor REST/NRSF binding to repressor element-1 (RE1) sequences in HD. High-throughput screening of thousands of selected compounds identified two benzoimidazole-5-carboxamide derivatives that inhibited REST silencing in a RE1-dependent manner. Treatment of 72 CAG NSCs with X5050 inhibitor, targeted REST degradation, increased the expressions of BDNF and other REST-regulated genes [95]. In 2013, Guo et al. developed a selective inhibitor (P110-TAT) of the mitochondrial fission protein dynaminrelated protein 1 (DRP1). Treatment of iPSC-derived neurons from HD patients with P110-TAT reduced mitochondrial fragmentation and improved mitochondrial function. Furthermore, P110-TAT increased cell viability and reduced the extent of neurite shortening in neuronal culture [96].

\section{Concluding Remarks}

The iPSC technology is a novel and complementary approach to studying neurological diseases.

Generation of human iPSC-derived neuronal cells enables the understanding of neural development and neuropathological processes in a more accessible manner than has previously been achieved. Rapid progress is being made in improving techniques for differentiation of iPSCs towards diverse populations of neural subtypes. Generation of hiPSC-derived cholinergic neurons will broaden our knowledge about mechanisms of cholinergic function during development and synaptic plasticity. The ability to selectively control neuronal differentiation of PSCs into functional neurons expressing cholinergic neurotransmitters and receptors is a significant step in understanding neurodegenerative diseases. Furthermore, it can be used for the development of cell replacement therapy for Alzheimer's disease and high-throughput screening for agents that promote BFCNs survival. The in vitro generated biologically functional DA neurons offer a renewable source for toxicological and pharmaceutical drug screening. They may provide an effective tool in the development of sustainable therapies for disorders that affect the DA system such as Parkinson's disease.

Despite the above-mentioned advantages, there are still some hurdles in expanding the use of iPSCs to study neurological diseases. First, there is lack of uniformity in culture techniques and induction methods that make unclear how reproducible differentiation protocols are. Methods based on neuronal differentiation in three-dimensional systems seem to be more efficient than adherent two-dimensional cultures. However, it is not determined which system is more adequate for in vivo environment. Second, a better characterization of a given neural subtypes is needed as well as verification whether newly generated neurons are able to integrate into the circuitry of a host organism. Neurons derived from hiPSCs required few weeks of culture to become electrophysiologically active and few months to integrate into the host neural environment after transplantation. Thus, the proper model system must be considered for assessing the function of human stem cell derived neurons and evaluating their safety in the long-term culture. Another difficulty is related to a variability of the iPSCs phenotypes within the cell lines, even if they are derived from the same patient. The iPSC variations can originate from different sources during iPSC generation and maintenance. Therefore, strong emphasis should be placed on demonstrating that phenotype of iPSC-derived neurons is associated with specific genetic background and not with this variability. The potential source of the line-to-line variation is the reprogramming process that may disturb the genomic and epigenetic stability and potentially introduces de novo epigenetic variations. Furthermore, during a clonal selection process, clones carrying genetic defects can be selected, while the increasing passage number might introduce genetic alterations that facilitate cell propagation. Such genetic and epigenetic variations between different iPSCs lines may affect the differentiation potential and undermine the iPSCs accountability in downstream applications. Thus, several iPSC lines from the same individual are necessary to monitor the phenotypic variability between these lines.

Despite the above limitations, patient-specific iPSCderived neurons provide an opportunity to model disease process in vitro. iPSCs carrying the genetic background and epigenetic pattern of the host individual can be a good tool to study the multifactorial diseases. One of the most challenging issues in disease modeling is the identification of the disease phenotype of neurons from patients. The difficulties are particularly visible in studying neurodegenerative disorders which evolve over several decades in vivo. Therefore, a reconstruction of cellular environment and interactions between the cells under the disease conditions can facilitate a proper phenotype development.

In conclusion, recent studies confirmed that iPSCs can accelerate drug discovery and might be applied for cell transplantation. In particular, ESC/iPSC-derived cholinergic and dopaminergic interneurons resulted in improved neurodegenerative diseases models, thus complementing animal models and accelerating the translation towards patient subgroup stratified clinical trials. We predict that iPSCs derived neural cells will be suitable to be used in various applications of in vitro disease modeling, high-throughput or high-content drug, and toxicology screening and potentially, in cell-transplant-mediated therapeutic interventions.

\section{Abbreviations}

2D: 2-dimensional

3D: 3-dimensional

3-NT: 3-Nitrotyrosine

6-OHDA: 6-Hydroxydopamine

AA: Ascorbic acid 


\begin{tabular}{|c|c|}
\hline $\mathrm{A} \beta:$ & Amyloid beta \\
\hline ACh: & Acetylcholine \\
\hline AChE: & Acetylcholinesterase \\
\hline $\mathrm{AD}:$ & Alzheimer's disease \\
\hline ALS: & Amyotrophic lateral sclerosis \\
\hline APP: & Amyloid precursor protein \\
\hline APP-CTF: & $\begin{array}{l}\text { C-terminal fragments of amyloid } \\
\text { precursor protein }\end{array}$ \\
\hline ASD: & Autism spectrum disorder \\
\hline ATM: & Ataxia-telangiectasia mutated \\
\hline BDNF: & Brain derived neurotrophic factor \\
\hline BFCN: & Basal forebrain cholinergic neurons \\
\hline BMP: & Bone morphogenic protein \\
\hline BMP9: & Bone morphogenic protein 9 \\
\hline cAMP: & Cyclic adenosine $3^{\prime}, 5^{\prime}$-monophosphate \\
\hline ChAT: & Choline acetyltransferase \\
\hline CDX2: & Caudal type homeobox 2 \\
\hline CNS: & Central nervous system \\
\hline CNTF: & Ciliary neurotrophic factor \\
\hline DA: & Dopaminergic \\
\hline DAPT: & $\begin{array}{l}\text { N-[N-(3,5-Difluorophenacetyl)-1-alanyl]- } \\
\text { S-phenylglycine t-butyl } \\
\text { ester }\end{array}$ \\
\hline DAT: & Dopamine transporter \\
\hline DHA: & Docosahexaenoic acid \\
\hline DNM1L: & Dynamin 1-like \\
\hline DRP1: & Dynamin-related protein 1 \\
\hline EGF: & Epidermal growth factor \\
\hline EN1: & Engrailed 1 \\
\hline ER: & Endoplasmic reticulum \\
\hline fAD: & Familial Alzheimer's disease \\
\hline FGF: & Fibroblast growth factor \\
\hline FGF8: & Fibroblast growth factor 8 \\
\hline FOXA2: & Fork head box protein $\mathrm{A} 2$ \\
\hline FP: & Floor plate \\
\hline GBA: & Beta-glucocerebrosidase \\
\hline GBX1: & Gastrulation brain homeobox 1 \\
\hline GDNF: & Glial cell line derived neurotrophic factor \\
\hline GPR52: & G-protein coupled receptor 52 \\
\hline GSK3B: & Glycogen synthase kinase 3 beta \\
\hline GSK3Bi: & GSK3B inhibitor \\
\hline GSMs: & $\gamma$-Secretase modulators \\
\hline GSAP: & $\gamma$-Secretase activating protein \\
\hline HD: & Huntington's disease \\
\hline hESC: & Human embryonic stem cell \\
\hline hiPSC: & Human induced pluripotent stem cell \\
\hline hPSC: & Human pluripotent stem cell \\
\hline HTT: & Huntingtin \\
\hline ISL1: & ISL LIM homeobox 1 \\
\hline KLF4: & Kruppel-like factor 4 \\
\hline KSR medium: & Knockout serum replacement \\
\hline Lhx6: & LIM homeobox 6 \\
\hline Lhx8: & LIM homeobox 8 \\
\hline LM511-E8: & $\begin{array}{l}\text { Recombinant E8 fragments of human } \\
\text { laminin } 511\end{array}$ \\
\hline LMX1A: & $\begin{array}{l}\text { LIM homeobox transcription factor } 1 \\
\text { alpha }\end{array}$ \\
\hline LRRK2: & Leucine-rich repeat kinase 2 \\
\hline LTP: & Long-term potentiation \\
\hline
\end{tabular}

mESC: $\quad$ Mouse embryonic stem cell

MGE: $\quad$ Median ganglionic eminence

miR196a: microRNA 196a

NCAM: Neural cell adhesion molecule

NES: Nestin

NFT: Neurofibrillary tangle

NGF: $\quad$ Nerve growth factor

NGFR: Nerve growth factor receptor

NKX2-1: $\quad$ NK2 homeobox 1

NRSF: $\quad$ Neuron restrictive silencer factor

NSAIDs: Nonsteroidal anti-inflammatory drugs

NSC: $\quad$ Neural stem cell

NTF3: $\quad$ Neurothrophin 3

NTF4: Neurothrophin 4

NTN1: $\quad$ Netrin 1

OCT4: $\quad$ Octamer-binding transcription factor 4

OTX2: Orthodenticle homeobox 2

PARK2: $\quad$ Parkin RBR E3 Ubiquitin Protein Ligase

PAX6: $\quad$ Paired box 6

PD: $\quad$ Parkinson's disease

PDL: $\quad$ Poly-D-Lysine

PKC: $\quad$ Protein kinase $\mathrm{C}$

PPAR $\delta$ Peroxisome proliferator activated receptor gamma

PPARGC1A: Peroxisome proliferator-activated receptor gamma, coactivator 1 alpha

PINK1: $\quad$ PTEN-induced putative kinase 1

PNS: $\quad$ Peripheral nervous system

POU5F1: $\quad$ POU domain, class 5, transcription factor 1

PSEN1: $\quad$ Presenilin 1

PSEN2: $\quad$ Presenilin 2

RA: Retinoic acid

RE1: $\quad$ Repressor element-1

REST: Repressor element-1 silencing

$\begin{array}{ll} & \text { transcription factor } \\ \text { ROCK: } & \text { Rho-associated coiled-coil forming }\end{array}$

protein serine/threonine kinase

sAD: $\quad$ Sporadic Alzheimer's disease

SHH: $\quad$ Sonic hedgehog

SMA: $\quad$ Spinal muscular atrophy

SNC: $\quad$ Substantia nigra pars compacta

SNCA: $\quad$ Synuclein alpha

SOX1: $\quad$ Sex determining region Y-box 1

SOX2: $\quad$ Sex determining region Y-box 2

TGFB3: $\quad$ Transforming growth factor, beta 3

TH: Tyrosine hydroxylase

TNF $\alpha$ : Tumor necrosis factor-alpha

TUBB3: $\quad$ Tubulin, Beta 3 Class III

UCHL1: Ubiquitin carboxyl-terminal esterase L1

VAChT: Vesicular acetylcholine transporter

WNT: Wingless-Type MMTV Integration Site Family.

\section{Competing Interests}

The authors declare that they have no competing interests. 


\section{Authors' Contributions}

Anna Ochalek and Karolina Szczesna have written the manuscript, Julianna Kobolak and Paolo Petazzi edited the manuscript, and Andras Dinnyes edited and approved the final version of the manuscript. All authors read and approved the final version.

\section{Acknowledgments}

The authors are grateful to Professor Karl-Heinz Krause, Dr. Balázs Mihalik, and Cormac Murphy for their suggestions for improving our manuscript. This work was supported by grants from EU FP7 projects (STEMMAD, PIAPPGA-2012-324451; EpiHealth, HEALTH-2012-F2-278418; EpiHealthNet, PITN-GA-2012-317146) and Szent Istvan University (Research Center of Excellence 11476-3/2016/FEKUT).

\section{References}

[1] A. B. Young, "Four decades of neurodegenerative disease research: how far we have come!," Journal of Neuroscience, vol. 29, no. 41, pp. 12722-12728, 2009.

[2] J. A. Thomson, J. Itskovitz-Eldor, S. S. Shapiro et al., "Embryonic stem cell lines derived from human blastocysts," Science, vol. 282, no. 5391, pp. 1145-1147, 1998.

[3] K. Takahashi, K. Tanabe, M. Ohnuki et al., "Induction of pluripotent stem cells from adult human fibroblasts by defined factors," Cell, vol. 131, no. 5, pp. 861-872, 2007.

[4] M. F. Pera, B. Reubinoff, and A. Trounson, "Human embryonic stem cells," Journal of Cell Science, vol. 113, no. 1, pp. 5-10, 2000.

[5] C. A. Ross and S. S. Akimov, "Human-induced pluripotent stem cells: potential for neurodegenerative diseases," Human Molecular Genetics, vol. 23, no. 1, pp. R17-R26, 2014.

[6] N. Bertrand, D. S. Castro, and F. Guillemot, "Proneural genes and the specification of neural cell types," Nature Reviews Neuroscience, vol. 3, no. 7, pp. 517-530, 2002.

[7] T. Halevy and A. Urbach, "Comparing ESC and iPSCbased models for human genetic disorders," Journal of Clinical Medicine, vol. 3, no. 4, pp. 1146-1162, 2014.

[8] A. L. Perrier, V. Tabar, T. Barberi et al., "Derivation of midbrain dopamine neurons from human embryonic stem cells," Proceedings of the National Academy of Sciences of the United States of America, vol. 101, no. 34, pp. 12543-12548, 2004.

[9] S. M. Chambers, C. A. Fasano, E. P. Papapetrou, M. Tomishima, M. Sadelain, and L. Studer, "Highly efficient neural conversion of human ES and iPS cells by dual inhibition of SMAD signaling," Nature Biotechnology, vol. 27, no. 3, pp. 275-280, 2009.

[10] S. Kriks, J.-W. Shim, J. Piao et al., "Dopamine neurons derived from human ES cells efficiently engraft in animal models of Parkinson's disease," Nature, vol. 480, no. 7378, pp. 547-551, 2011.

[11] D. Doi, B. Samata, M. Katsukawa et al., "Isolation of human induced pluripotent stem cell-derived dopaminergic progenitors by cell sorting for successful transplantation," Stem Cell Reports, vol. 2, no. 3, pp. 337-350, 2014.

[12] C. J. Bissonnette, L. Lyass, B. J. Bhattacharyya, A. Belmadani, R. J. Miller, and J. A. Kessler, "The controlled generation of functional basal forebrain cholinergic neurons from human embryonic stem cells," STEM CELLS, vol. 29, no. 5, pp. 802-811, 2011.
[13] L. Wicklund, R. N. Leão, A.-M. Strömberg et al., “ $\beta$-Amyloid 1-42 oligomers impair function of human embryonic stem cellderived forebrain cholinergic neurons," PLoS ONE, vol. 5, no. 12, Article ID e15600, 2010.

[14] L. A. Crompton, M. L. Byrne, H. Taylor et al., "Stepwise, non-adherent differentiation of human pluripotent stem cells to generate basal forebrain cholinergic neurons via hedgehog signaling," Stem Cell Research, vol. 11, no. 3, pp. 1206-1221, 2013.

[15] M. Nilbratt, O. Porras, A. Marutle, O. Hovatta, and A. Nordberg, "Neurotrophic factors promote cholinergic differentiation in human embryonic stem cell-derived neurons," Journal of Cellular and Molecular Medicine, vol. 14, no. 6, pp. 1476-1484, 2010.

[16] X. Zeng, J. Cai, J. Chen et al., "Dopaminergic differentiation of human embryonic stem cells," Stem Cells, vol. 22, no. 6, pp. 925940, 2004.

[17] W. Ye, K. Shimamura, J. L. R. Rubenstein, M. A. Hynes, and A. Rosenthal, "FGF and Shh signals control dopaminergic and serotonergic cell fate in the anterior neural plate," Cell, vol. 93, no. 5, pp. 755-766, 1998.

[18] A. Young, K. S. Assey, C. D. Sturkie, F. D. West, D. W. Machacek, and S. L. Stice, "Glial cell line-derived neurotrophic factor enhances in vitro differentiation of mid-/hindbrain neural progenitor cells to dopaminergic-like neurons," Journal of Neuroscience Research, vol. 88, no. 15, pp. 3222-3232, 2010.

[19] S.-H. Lee, N. Lumelsky, L. Studer, J. M. Auerbach, and R. D. McKay, "Efficient generation of midbrain and hindbrain neurons from mouse embryonic stem cells," Nature Biotechnology, vol. 18, no. 6, pp. 675-679, 2000.

[20] H. Kawasaki, K. Mizuseki, S. Nishikawa et al., "Induction of midbrain dopaminergic neurons from ES cells by stromal cellderived inducing activity," Neuron, vol. 28, no. 1, pp. 31-40, 2000.

[21] Y. Yan, D. Yang, E. D. Zarnowska et al., "Directed differentiation of dopaminergic neuronal subtypes from human embryonic stem cells," Stem Cells, vol. 23, no. 6, pp. 781-790, 2005.

[22] D. Yang, Z.-J. Zhang, M. Oldenburg, M. Ayala, and S. U.-C. Zhang, "Human embryonic stem cell-derived dopaminergic neurons reverse functional deficit in Parkinsonian rats," Stem Cells, vol. 26, no. 1, pp. 55-63, 2008.

[23] O. Cooper, G. Hargus, M. Deleidi et al., "Differentiation of human ES and Parkinson's disease iPS cells into ventral midbrain dopaminergic neurons requires a high activity form of SHH, FGF8a and specific regionalization by retinoic acid," Molecular and Cellular Neuroscience, vol. 45, no. 3, pp. 258-266, 2010.

[24] Y. Ono, T. Nakatani, Y. Sakamoto et al., "Differences in neurogenic potential in floor plate cells along an anteroposterior location: midbrain dopaminergic neurons originate from mesencephalic floor plate cells," Development, vol. 134, no. 17, pp. 3213-3225, 2007.

[25] S. Chung, A. Leung, B.-S. Han et al., "Wnt1-lmxla forms a novel autoregulatory loop and controls midbrain dopaminergic differentiation synergistically with the SHH-FoxA2 pathway," Cell Stem Cell, vol. 5, no. 6, pp. 646-658, 2009.

[26] C. A. Fasano, S. M. Chambers, G. Lee, M. J. Tomishima, and L. Studer, "Efficient derivation of functional floor plate tissue from human embryonic stem cells," Cell Stem Cell, vol. 6, no. 4, pp. 336-347, 2010.

[27] P. Mohapel, G. Leanza, M. Kokaia, and O. Lindvall, "Forebrain acetylcholine regulates adult hippocampal neurogenesis and learning," Neurobiology of Aging, vol. 26, no. 6, pp. 939-946, 2005. 
[28] N. Kuczewski, E. Aztiria, G. Leanza, and L. Domenici, "Selective cholinergic immunolesioning affects synaptic plasticity in developing visual cortex," European Journal of Neuroscience, vol. 21, no. 7, pp. 1807-1814, 2005.

[29] K. Matsumoto, T. Tanaka, T. Furuyama et al., "L3, a novel murine LIM-homeodomain transcription factor expressed in the ventral telencephalon and the mesenchyme surrounding the oral cavity," Neuroscience Letters, vol. 204, no. 1-2, pp. 113-116, 1996.

[30] C. H. J. Asbreuk, H. S. A. Van Schaick, J. Cox, M. Kromkamp, M. P. Smidt, and J. P. H. Burbach, "The homeobox genes Lhx7 and Gbxl are expressed in the basal forebrain cholinergic system," Neuroscience, vol. 109, no. 2, pp. 287-298, 2002.

[31] M. V. Chao, "Neurotrophins and their receptors: a convergence point for many signalling pathways," Nature Reviews Neuroscience, vol. 4, no. 4, pp. 299-309, 2003.

[32] J. Ericson, J. Muhr, M. Placzek, T. Lints, T. M. Jessel, and T. Edlund, "Sonic hedgehog induces the differentiation of ventral forebrain neurons: a common signal for ventral patterning within the neural tube," Cell, vol. 81, no. 5, pp. 747-756, 1995.

[33] Y. Hu, Z. Qu, S. Cao et al., "Directed differentiation of basal forebrain cholinergic neurons from human pluripotent stem cells," Journal of Neuroscience Methods, vol. 266, pp. 42-49, 2016.

[34] Alzheimer's Association, "2015 Alzheimer's disease facts and figures," Alzheimer's \& Dementia, vol. 11, no. 3, pp. 332-384, 2015.

[35] A. M. Tata, L. Velluto, C. D’angelo, and M. Reale, "Cholinergic system dysfunction and neurodegenerative diseases: cause or effect?" CNS and Neurological Disorders-Drug Targets, vol. 13, no. 7, pp. 1294-1303, 2014.

[36] D. M. Holtzman, J. C. Morris, and A. M. Goate, "Alzheimer's disease: the challenge of the second century," Science Translational Medicine, vol. 3, no. 77, Article ID 77srl, 2011.

[37] M. R. Farlow, "Randomized clinical trial results for donepezil in Alzheimer's disease: is the treatment glass half full or half empty?" Journal of the American Geriatrics Society, vol. 56, no. 8, pp. 1566-1567, 2008.

[38] A. Castro and A. Martinez, "Peripheral and dual binding site acetylcholinesterase inhibitors: implications in treatment of Alzheimer's disease," Mini reviews in medicinal chemistry, vol. 1, no. 3, pp. 267-272, 2001.

[39] E. Karran, M. Mercken, and B. De Strooper, "The amyloid cascade hypothesis for Alzheimer's disease: an appraisal for the development of therapeutics," Nature Reviews Drug Discovery, vol. 10, no. 9, pp. 698-712, 2011.

[40] T. Kondo, M. Asai, K. Tsukita et al., "Modeling Alzheimer's disease with iPSCs reveals stress phenotypes associated with intracellular $\mathrm{A} \beta$ and differential drug responsiveness," Cell Stem Cell, vol. 12, no. 4, pp. 487-496, 2013.

[41] C. R. Muratore, H. C. Rice, P. Srikanth et al., "The familial Alzheimer's disease APPV717I mutation alters APP processing and Tau expression in iPSC-derived neurons," Human Molecular Genetics, vol. 23, no. 13, Article ID ddu064, pp. 3523-3536, 2014.

[42] M. A. Israel, S. H. Yuan, C. Bardy et al., "Probing sporadic and familial Alzheimer's disease using induced pluripotent stem cells," Nature, vol. 482, no. 7384, pp. 216-220, 2012.

[43] T. Yagi, D. Ito, Y. Okada et al., "Modeling familial Alzheimer's disease with induced pluripotent stem cells," Human Molecular Genetics, vol. 20, no. 23, pp. 4530-4539, 2011.
[44] A. K. Ghosh, M. Brindisi, and J. Tang, "Developing $\beta$-secretase inhibitors for treatment of Alzheimer's disease," Journal of Neurochemistry, vol. 120, no. 1, pp. 71-83, 2012.

[45] B. P. Imbimbo and G. A. M. Giardina, " $\gamma$-Secretase inhibitors and modulators for the treatment of Alzheimer's disease: disappointments and hopes," Current Topics in Medicinal Chemistry, vol. 11, no. 12, pp. 1555-1570, 2011.

[46] J. Mertens, K. Stüber, P. Wunderlich et al., "APP processing in human pluripotent stem cell-derived neurons is resistant to NSAID-based $\gamma$-secretase modulation," Stem Cell Reports, vol. 1, no. 6, pp. 491-498, 2013.

[47] T. M. Dawson, "New animal models for Parkinson's disease," Cell, vol. 101, no. 2, pp. 115-118, 2000.

[48] W. Wan, L. Cao, B. Kalionis, S. Xia, and X. Tai, "Applications of induced pluripotent stem cells in studying the neurodegenerative diseases," Stem Cells International, vol. 2015, Article ID 382530, 11 pages, 2015.

[49] S. B. Dunnett and A. Björklund, "Prospects for new restorative and neuroprotective treatments in Parkinson's disease," Nature, vol. 399, no. 6738, supplement, pp. A32-A39, 1999.

[50] F. H. Lewy, "Zur pathologischen Anatomie der Paralysis agitans," Dtsch Ztscgr Nervenheilkd, vol. 50, pp. 50-55, 1913.

[51] A. E. Lang and A. M. Lozano, "Parkinson's disease. First of two parts," The New England Journal of Medicine, vol. 339, no. 15, pp. 1044-1053, 1998.

[52] B. Byers, B. Cord, H. N. Nguyen et al., "SNCA triplication Parkinson's patient's iPSC-Derived DA neurons accumulate $\alpha$ synuclein and are susceptible to oxidative stress," PLOS ONE, vol. 6, no. 11, Article ID e26159, 2011.

[53] C. Y. Chung, V. Khurana, P. K. Auluck et al., "Identification and rescue of $\alpha$-synuclein toxicity in Parkinson patient-derived neurons," Science, vol. 342, no. 6161, pp. 983-987, 2013.

[54] H. N. Nguyen, B. Byers, B. Cord et al., "LRRK2 mutant iPSCderived da neurons demonstrate increased susceptibility to oxidative stress," Cell Stem Cell, vol. 8, no. 3, pp. 267-280, 2011.

[55] A. Sánchez-Danés, Y. Richaud-Patin, I. Carballo-Carbajal et al., "Disease-specific phenotypes in dopamine neurons from human iPS-based models of genetic and sporadic Parkinson's disease," EMBO Molecular Medicine, vol. 4, no. 5, pp. 380-395, 2012.

[56] F. Soldner, D. Hockemeyer, C. Beard et al., "Parkinson's disease patient-derived induced pluripotent stem cells free of viral reprogramming factors," Cell, vol. 136, no. 5, pp. 964-977, 2009.

[57] P. Seibler, J. Graziotto, H. Jeong, F. Simunovic, C. Klein, and D. Krainc, "Mitochondrial parkin recruitment is impaired in neurons derived from mutant PINK1 induced pluripotent stem cells," Journal of Neuroscience, vol. 31, no. 16, pp. 5970-5976, 2011.

[58] H. Jiang, Y. Ren, E. Y. Yuen et al., "Parkin controls dopamine utilization in human midbrain dopaminergic neurons derived from induced pluripotent stem cells," Nature Communications, vol. 3, article 668, 2012.

[59] M. Wernig, J.-P. Zhao, J. Pruszak et al., "Neurons derived from reprogrammed fibroblasts functionally integrate into the fetal brain and improve symptoms of rats with Parkinson's disease," Proceedings of the National Academy of Sciences of the United States of America, vol. 105, no. 15, pp. 5856-5861, 2008.

[60] G. Hargus, O. Cooper, M. Deleidi et al., "Differentiated Parkinson patient-derived induced pluripotent stem cells grow in the adult rodent brain and reduce motor asymmetry in Parkinsonian rats," Proceedings of the National Academy of Sciences of the United States of America, vol. 107, no. 36, pp. 15921-15926, 2010. 
[61] Y.-H. Rhee, J.-Y. Ko, M.-Y. Chang et al., "Protein-based human iPS cells efficiently generate functional dopamine neurons and can treat a rat model of Parkinson disease," Journal of Clinical Investigation, vol. 121, no. 6, pp. 2326-2335, 2011.

[62] Y. Kishi, J. Takahashi, M. Koyanagi et al., "Estrogen promotes differentiation and survival of dopaminergic neurons derived from human neural stem cells," Journal of Neuroscience Research, vol. 79, no. 3, pp. 279-286, 2005.

[63] N. I. Bohnen and R. L. Albin, "The cholinergic system and Parkinson disease," Behavioural Brain Research, vol. 221, no. 2, pp. 564-573, 2011.

[64] A. D. Ebert, J. Yu, F. F. Rose Jr. et al., "Induced pluripotent stem cells from a spinal muscular atrophy patient," Nature, vol. 457, no. 7227, pp. 277-280, 2009.

[65] I. Faravelli, E. Frattini, A. Ramirez, G. Stuppia, M. Nizzardo, and S. Corti, "iPSC-based models to unravel key pathogenetic processes underlying motor neuron disease development," Journal of Clinical Medicine, vol. 3, no. 4, pp. 1124-1145, 2014.

[66] B. Bilican, A. Serio, S. J. Barmada et al., "Mutant induced pluripotent stem cell lines recapitulate aspects of TDP- 43 proteinopathies and reveal cell-specific vulnerability," Proceedings of the National Academy of Sciences of the United States of America, vol. 109, no. 15, pp. 5803-5808, 2012.

[67] H. Chen, K. Qian, Z. Du et al., "Modeling ALS with iPSCs reveals that mutant SOD1 misregulates neurofilament balance in motor neurons," Cell Stem Cell, vol. 14, no. 6, pp. 796-809, 2014.

[68] L. Aliaga, C. Lai, J. Yu et al., "Amyotrophic lateral sclerosisrelated VAPB P56S mutation differentially affects the function and survival of corticospinal and spinal motor neurons," Human Molecular Genetics, vol. 22, no. 21, pp. 4293-4305, 2013.

[69] M. C. An, N. Zhang, G. Scott et al., "Genetic correction of Huntington's disease phenotypes in induced pluripotent stem cells," Cell Stem Cell, vol. 11, no. 2, pp. 253-263, 2012.

[70] I.-H. Park, N. Arora, H. Huo et al., "Disease-specific induced pluripotent stem cells," Cell, vol. 134, no. 5, pp. 877-886, 2008.

[71] I. Jeon, C. Choi, N. Lee et al., "In vivo roles of a patient-derived induced pluripotent stem cell line (HD72-iPSC) in the YAC128 model of huntington's disease," International Journal of Stem Cells, vol. 7, no. 1, pp. 43-47, 2014.

[72] W. Le Goff, M. Settle, D. J. Greene, R. E. Morton, and J. D. Smith, "Reevaluation of the role of the multidrug-resistant P-glycoprotein in cellular cholesterol homeostasis," Journal of Lipid Research, vol. 47, no. 1, pp. 51-58, 2006.

[73] G. Lee, E. P. Papapetrou, H. Kim et al., "Modelling pathogenesis and treatment of familial dysautonomia using patient-specific iPSCs," Nature, vol. 461, no. 7262, pp. 402-406, 2009.

[74] N. Farra, W.-B. Zhang, P. Pasceri, J. H. Eubanks, M. W. Salter, and J. Ellis, "Rett syndrome induced pluripotent stem cellderived neurons reveal novel neurophysiological alterations," Molecular Psychiatry, vol. 17, no. 12, pp. 1261-1271, 2012.

[75] U. Djuric, A. Y. L. Cheung, W. Zhang et al., "MECP2el isoform mutation affects the form and function of neurons derived from Rett syndrome patient iPS cells," Neurobiology of Disease, vol. 76, pp. 37-45, 2015.

[76] D.-S. Kim, P. Joel Ross, K. Zaslavsky, and J. Ellis, “Optimizing neuronal differentiation from induced pluripotent stem cells to model ASD," Frontiers in Cellular Neuroscience, vol. 8, no. 1, article no. 109, 2014.
[77] L. Zeng, P. Zhang, L. Shi, V. Yamamoto, W. Lu, and K. Wang, "Functional impacts of NRXN1 knockdown on neurodevelopment in stem cell models," PLoS ONE, vol. 8, no. 3, Article ID e59685, 2013.

[78] C. Chen, P. Jiang, H. Xue et al., "Role of astroglia in Down's syndrome revealed by patient-derived human-induced pluripotent stem cells," Nature Communications, vol. 5, article 4430, 2014.

[79] L. B. Li, K.-H. Chang, P.-R. Wang, R. K. Hirata, T. Papayannopoulou, and D. W. Russell, "Trisomy correction in down syndrome induced pluripotent stem cells," Cell Stem Cell, vol. 11, no. 5, pp. 615-619, 2012.

[80] J. Jiang, Y. Jing, G. J. Cost et al., “Translating dosage compensation to trisomy 21," Nature, vol. 500, no. 7462, pp. 296-300, 2013.

[81] K. J. Brennand, M. A. Landek-Salgado, and A. Sawa, "Modeling heterogeneous patients with a clinical diagnosis of schizophrenia with induced pluripotent stem cells," Biological Psychiatry, vol. 75, no. 12, pp. 936-944, 2014.

[82] P. A. Thomson, E. L. V. Malavasi, E. Grünewald, D. C. Soares, M. Borkowska, and J. K. Millar, "DISC1 genetics, biology and psychiatric illness," Frontiers in Biology, vol. 8, no. 1, pp. 1-31, 2013.

[83] S. Claes, K. Van Zand, E. Legius et al., "Correlations between triplet repeat expansion and clinical features in Huntington's disease," Archives of Neurology, vol. 52, no. 8, pp. 749-753, 1995.

[84] H. J. Waldvogel, E. H. Kim, L. J. Tippett, J.-P. G. Vonsattel, and R. L. M. Faull, "The neuropathology of Huntington's disease," Current Topics in Behavioral Neurosciences, vol. 22, pp. 33-80, 2014.

[85] R. Smith, H. Chung, S. Rundquist et al., "Cholinergic neuronal defect without cell loss in Huntington's disease," Human Molecular Genetics, vol. 15, no. 21, pp. 3119-3131, 2006.

[86] M. Shimojo and L. B. Hersh, "Regulation of the cholinergic gene locus by the repressor element-1 silencing transcription factor/neuron restrictive silencer factor (REST/NRSF)," Life Sciences, vol. 74, no. 18, pp. 2213-2225, 2004.

[87] I. Jeon, N. Lee, J.-Y. Li et al., "Neuronal properties, in vivo effects, and pathology of a Huntington's disease patient-derived induced pluripotent stem cells," Stem Cells, vol. 30, no. 9, pp. 2054-2062, 2012.

[88] A. Tousley and K. B. Kegel-Gleason, "Induced pluripotent stem cells in huntington's disease research: progress and opportunity," Journal of Huntington's Disease, vol. 5, no. 2, pp. 99-131, 2016.

[89] H.-Y. Hsiao, F.-L. Chiu, C.-M. Chen et al., "Inhibition of soluble tumor necrosis factor is therapeutic in Huntington's disease," Human Molecular Genetics, vol. 23, no. 16, pp. 4328-4344, 2014.

[90] F.-L. Chiu, J.-T. Lin, C.-Y. Chuang et al., "Elucidating the role of the $\mathrm{A} 2 \mathrm{~A}$ adenosine receptor in neurodegeneration using neurons derived from Huntington's disease iPSCs," Human Molecular Genetics, vol. 24, no. 21, pp. 6066-6079, 2015.

[91] P.-H. Cheng, C.-L. Li, Y.-F. Chang et al., "MiR-196a ameliorates phenotypes of huntington disease in cell, transgenic mouse, and induced pluripotent stem cell models," American Journal of Human Genetics, vol. 93, no. 2, pp. 306-312, 2013.

[92] A. S. Dickey, V. V. Pineda, T. Tsunemi et al., "PPAR- $\delta$ is repressed in Huntington's disease, is required for normal neuronal function and can be targeted therapeutically," Nature Medicine, vol. 22, no. 1, pp. 37-45, 2016.

[93] X.-H. Lu, V. B. Mattis, N. Wang et al., "Targeting ATM ameliorates mutant Huntingtin toxicity in cell and animal models 
of Huntington's disease," Science Translational Medicine, vol. 6, no. 268, p. 268, 2014.

[94] K. L. Ring, M. C. An, N. Zhang et al., "Genomic analysis reveals disruption of striatal neuronal development and therapeutic targets in human Huntington's disease neural stem cells," Stem Cell Reports, vol. 5, no. 6, pp. 1023-1038, 2015.

[95] J. Charbord, P. Poydenot, C. Bonnefond et al., "High throughput screening for inhibitors of REST in neural derivatives of human embryonic stem cells reveals a chemical compound that promotes expression of neuronal genes," STEM CELLS, vol. 31, no. 9, pp. 1816-1828, 2013.

[96] X. Guo, M.-H. Disatnik, M. Monbureau, M. Shamloo, D. Mochly-Rosen, and X. Qi, "Inhibition of mitochondrial fragmentation diminishes Huntington's disease-associated neurodegeneration," Journal of Clinical Investigation, vol. 123, no. 12, pp. 5371-5388, 2013. 

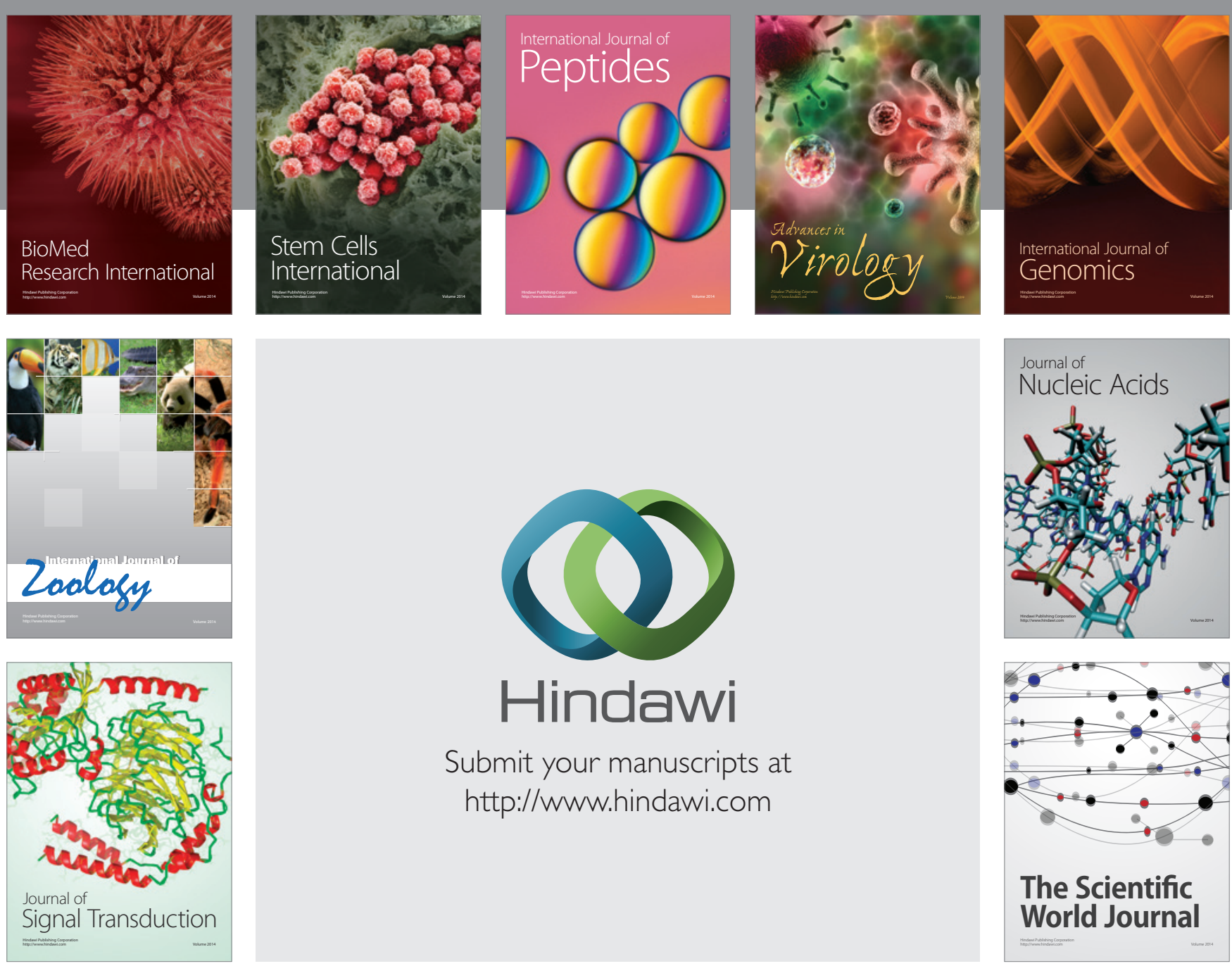

Submit your manuscripts at

http://www.hindawi.com
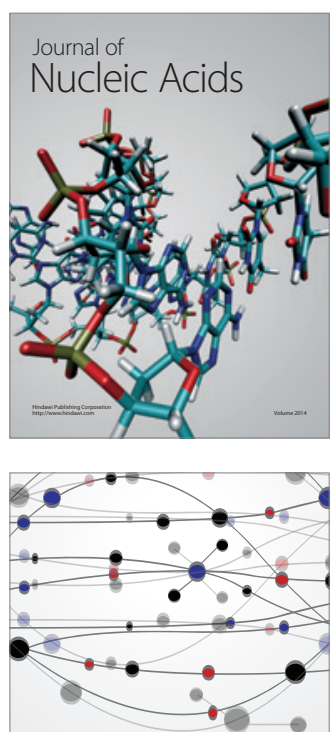

The Scientific World Journal
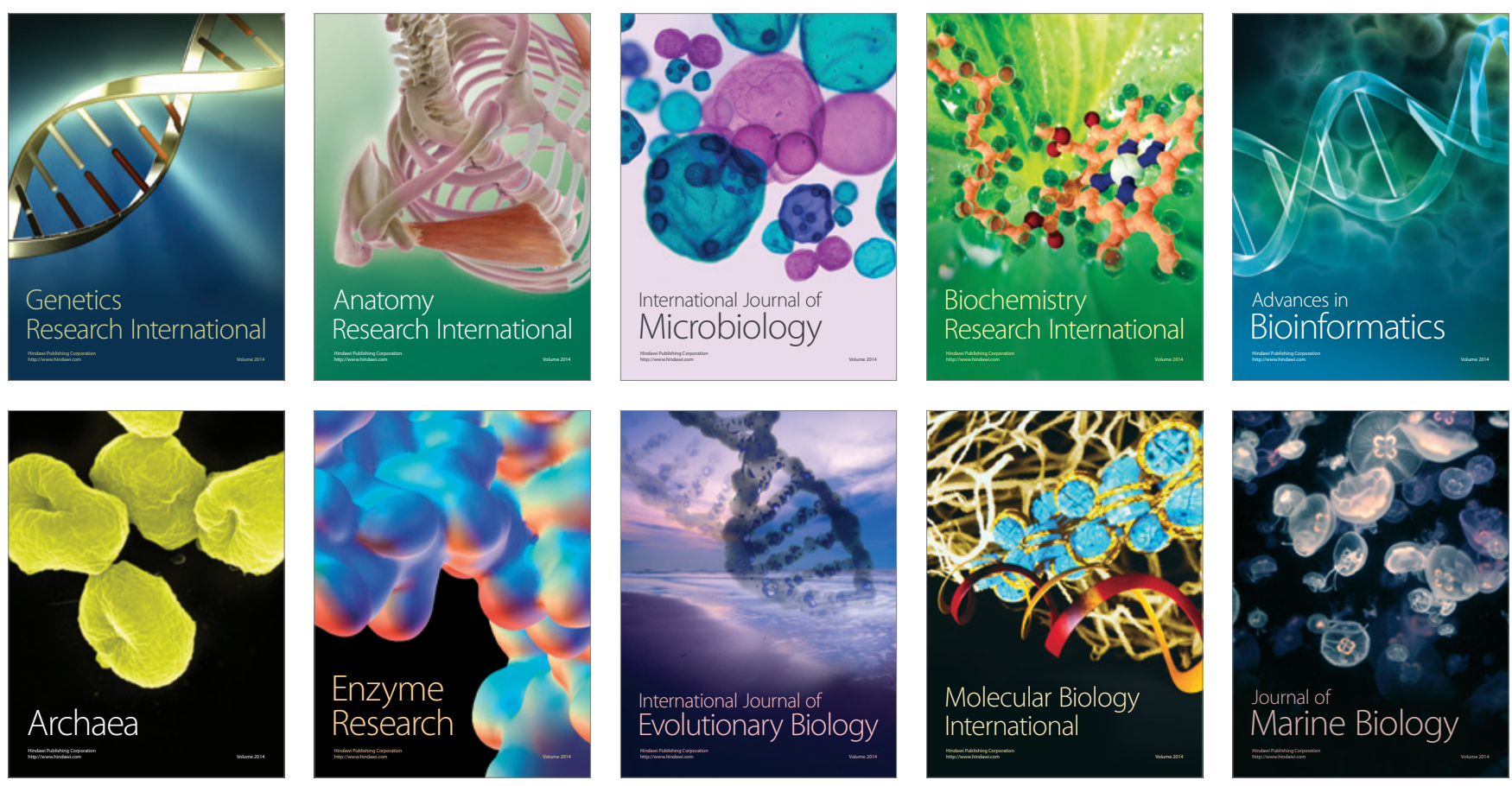